Arteterapia. Papeles de arteterapia y educación para inclusión social ISSN: $1886-6190$

\title{
Abordaje arteterapéutico con niños institucionalizados
}

\author{
Luis Formaiano ${ }^{1}$
}

Recibido: 23 de mayo de 2016 / Aceptado: 10 de julio de 2016

Resumen. Este trabajo presenta una experiencia de arteterapia con niños institucionalizados. Si bien se analizan varios estudios de casos, también se incluye una mirada sobre la institución en sí, como una variable imposible de ignorar a lo largo del desarrollo del proyecto arteterapéutico. Para el arteterapeuta en un ámbito institucional es fundamental el enfoque multidisciplinario, aunque veremos que en el caso presentado en este trabajo no necesariamente ha sido así.

Palabras clave: Arteterapia; Niñez; Privación; Equipo Multidisciplinario; Autoestima; Transferencia y Contratransferencia.

\section{[en] Art Therapy with Institutionalized Children}

Abstract. This paper describes an experience of group art therapy with institutionalized children. Although several case studies are examined, an overview of the institution in itself is included as a variable to be considered in any art therapy project. For any art therapist active in an institutional setting, it is essential to work hand in hand with a multidisciplinary team, although this has not necessarily been the case in this particular experience.

Keywords: Art Therapy; Childhood; Deprivation; Multidisciplinary team; Self Esteem; Transference. Counter transference.

Sumario. 1. Introducción; 2. Objetivos del proyecto; 3. Desarrollo del taller; 4. Estudios de casos; 5. Conclusiones; 6 . Referencias bibliográficas.

Cómo citar: Formaiano, L. (2016) Abordaje arteterapéutico con niños institucionalizados, en Arteterapia. Papeles de arteterapia y educación para inclusión social 11, 223-240.

1 Lic en Psicología (Universidad de Buenos Aires) - Arteterapeuta (IUNA). Docente de Especialización en Arteterapia Plástica CentrArT, Buenos Aires. Miembro Fundador Asociación Argentina de Arte Terapia. Miembro del Capítulo de Arte y Psiquiatría de APSA (Asoc de Psiquiatras Argentinos)

E-mail: luisformaiano@gmail.com 


\section{Introducción}

Los hogares donde se albergan niños y adolescentes, ya sea por haber sido judicializados o por alguna otra razón, representan un universo en sí mismos. Cada uno de los niños o adolescentes que allí están, seguramente tiene una historia no muy agradable que contar. El paso por una institución u hogar de acogida deja una marca imborrable en la vida de cada niño. El propósito de este tipo de instituciones es el de trabajar para lograr recomponer - dentro de lo posible - lo vincular con el grupo familiar primario, una tarea no exenta de avatares. Como claramente lo expresan Fernández Cao y Martínez Díez:

El niño desde su nacimiento en adelante, antes de aprender a hablar y reconocer la identidad de quienes les cuidan, responde al cuidado y al cariño, a los que responde con miradas o sonidos de placer. Muchos de los niños en casas de acogida, no han podido conocer ni los cuidados ni el cariño, son niños que presentan dificultades dadas las situaciones que les ha tocado vivir, el arte les sirve de ayuda para mejorar la comunicación con ellos mismos y con los demás, a sentirse valorados como personas, y adquirir seguridad y desarrollar su autoestima, ayudándoles a potenciar su imaginación creadora. (Fernández Cao; Martínez Díez, 2006:79)

El caso aquí presentado es el de una institución asistencial- o casa de acogida muy pequeña, de carácter público y que alberga una decena de niños de variadas edades. Al momento de la entrevista inicial se me informó que el hogar contaba con un equipo permanente de profesionales formado por una psicóloga, una psicopedagoga, una asistente social y un psiquiatra. Sin embargo, durante las semanas que duró el proyecto, nunca vi a ningún otro profesional en la institución -, algo de lo que dejé constancia en mi informe final, ya que el intercambio interdisciplinario habría enriquecido la mirada sobre cada niño.

También se barajó la posibilidad de que si la experiencia resultaba fructífera - y de hecho lo fue, porque los chicos esperaban anhelantes la hora de arteterapia existía la posibilidad de que se incorporase un arteterapeuta al equipo.

Es importante tener en cuenta que una de las principales características de los niños albergados en estos hogares es la agresividad, en muchos casos, mano a mano con mecanismos de negación y hasta delirios de grandeza. Las consecuencias de este cúmulo de necesidades insatisfechas, de miedos e inseguridades son notorias en que, según Edith Kramer:

En una atmósfera sobrecargada de agresión, no hay lugar para el complejo proceso de formación del yo. No hay demasiadas posibilidades para aprender a resolver conflictos por medios más maduros; la personalidad infantil permanece impulsiva y desestructurada. La inclinación a los berrinches, al odio irracional y a la furia pueden convertirse en una modalidad habitual... (Kramer, 1982: 41)

El grupo estaba formado por un grupo de tres hermanos, dos varones de 5 y 8 años (Carlitos y Julio) y una niña de 9 (Laura), luego otra familia de tres hermanos, 
un varón de 9 (Esteban), una niña de 7 (Raquel) y un bebé de un año, una tercera familia de tres hermanos, un varón de 9 años (Diego) y dos niñas de 11 y 12 años, respectivamente, (Alicia y Carmen) y, finalmente, otro varón de 5 años (Claudio), sin ningún lazo de parentesco.

Si bien los niños asistían a la escuela y tenían salidas programadas, muchas veces los encontré estresados porque debían concurrir al juzgado o tenían una visita médica. Por otro lado, estaban quienes llevaban poco tiempo en el hogar y no querían irse y otros, como los hermanos cuya producción examinaré en primer lugar, hacía ya tres años que estaban allí y no veían la hora de irse definitivamente. Lo primero que percibí, al conocerlos y verlos trabajar, fue su gran carencia afectiva y la necesidad de metabolizar esa vida ficticiamente ordenada, sin el apoyo de adultos significativos de referencia, sin miradas que proviniesen del amor materno o paterno.

Cada una de estas instituciones tiene su propia modalidad, por ejemplo, en otra experiencia con niños visité un hogar de acogida con una población de sesenta niños, en la que cada grupo de niños estaba a cargo de operadores convivenciales que estaban disponibles las 24 horas en tres turnos de 8 horas cada uno. Estos operadores trabajaban con la formación de hábitos, la calidad de vida y la enseñanza. Esta casa estaba considerada un instituto de destino, donde llegaban con la salida siempre en mente. Y seis meses antes de dejar la institución, entraban en un programa pre alta compuesto por interminables entrevistas, talleres, visitas a los padres y a los terapeutas de cada uno de ellos, además del juzgado interviniente. También manejaban modalidades de adopción, no siempre sin complejidades, ya que, en medio del proceso, la familia original del niño reaparecía, comenzando a visitarlo con frecuencia, entorpeciendo el proceso así iniciado, para luego volver a desaparecer.

Por eso considero muy necesario hacer un análisis minucioso de la institución (horarios, conformación de los espacios, personal, salidas, hábitos, actividades, etc), en suma, la cultura de la institución, ya que es lo único que va a permitir elaborar un proyecto con objetivos adecuados y consistentes con las características y modalidades institucionales y, fundamentalmente, centrado en el niño.

El espacio que se me adjudicó fue la sala donde los chicos tomaban sus comidas y hacían las tareas escolares, en las paredes no había absolutamente ninguna decoración o cuadros. Había un solo baño en planta baja, de uso común y una cocina. Los dormitorios y el televisor - donde podían ver vídeos - estaban en la planta superior.

La casa contaba con un jardín delantero y un patio en la parte trasera, que era un área de juego para los niños.

Es importante tener siempre presente que, como arteterapeutas, proponemos una herramienta de transformación, que, las más de las veces, puede llegar a confrontar lo instituido por su carácter fuertemente instituyente.

El espacio que se nos adjudica y el interés por nuestro trabajo son solo dos de las múltiples variables en juego que dan cuenta del grado de compromiso de la institución con el proyecto que proponemos. 


\section{Objetivos del proyecto}

Considerando las características de la institución y de la población que albergaba, me pareció pertinente trabajar ciertos ejes referidos al establecimiento de vínculos de confianza, no solo de cada niño consigo mismo, sino también con los que lo rodeaban, a través de:

- Recomponer/reconstituir

- Vincular desde lo grupal

- Fortalecer la autonomía

- Reforzar la autoestima

- Explorar los propios recursos

- Estimular la capacidad de imaginar y fantasear

Luego, en cada encuentro propuesto se trabajó un objetivo particular de acuerdo al siguiente cronograma orientativo - orientativo en el sentido de que ante la aparición de algo puntual y que convocase al grupo, se trabajaría ese emergente en particular:

\section{Primer Encuentro}

\section{Consigna: Un día de salida}

Objetivo: Explorar la percepción que cada niño tiene del mundo exterior, de aquello que

lo rodea (y a lo que está en vías de integrarse en un futuro). Una variable es trabajar a

qué lugares le gustaría ir.

Materiales: Hojas canson grandes, crayones y lápices de colores. Se trabajará de manera

bidimensional e individualmente.

Desarrollo: Cada participante dibujará, pintará, pegará, todos aquellos objetos o elementos

que le llamaron la atención en aquellos lugares en los que estuvo o que le gustaría ver en

una futura visita a algún lugar en particular.

\section{Segundo Encuentro}

Consigna: Mis cosas favoritas

Objetivo: Explorar la percepción del mundo interno de cada integrante a través de

elementos positivos.

Materiales: Hojas canson grandes, crayones, fibras y lápices de colores. Se trabajará de

manera bidimensional e individualmente.

Desarrollo: Cada participantes dibujará la silueta de una gran caja - contenedora - dentro

de la cual dibujará o pintará todos aquellos objetos, elementos, recuerdos o ideas que

considere importantes. 


\section{Tercer Encuentro}

\section{Consigna: Jugando con máscaras}

Objetivo: Explorar - a través de un personaje inventado - aquello que cada niño espera,

anhela o sueña.

Materiales: Papel corrugado, fibras, crayones, témperas, cintas, material de desecho y

tijeras. Se trabajará bidimensionalmente creando una máscara simple.

Desarrollo: Cada participante dibujará un óvalo (de acuerdo a una plantilla provista) sobre

el que identificará ojos, nariz, boca y orejas. La pintará a su gusto y luego atará una cinta de

cada extremo para poder ponérsela, si así lo desea.

Para terminar contará lo que el personaje de la máscara quiera expresar.

\section{Cuarto Encuentro}

\section{Consigna: Las Manos que hablan}

Objetivo: Primer acercamiento al trabajo grupal a partir de la puesta de la propia huella (mano) sobre un espacio de convivencia con las otras.

Materiales: Hojas canson grandes, papel de escenografía, fibras, crayones, témpera, tijera y Cola de pegar. Se trabajará bidimensionalmente, primero en forma individual y, luego, una puesta en común grupal.

Desarrollo: Cada sujeto hará un contorno de sus manos, que coloreará, recortará y pegará en una hoja de papel de escenografía junto con las de sus compañeros. Cada mano expresará una o más palabras. Todas las manos habrán de formar un mandala con un mensaje final colectivo consensuado por el grupo y que será incluido en el trabajo.

\section{Quinto Encuentro}

Consigna: Hola, yo soy...

Objetivo: El propósito es conocer a cada participante, ver cómo se presenta y qué elige mostrar de sí mismo.

Materiales: Hojas canson blancas grandes, fibras, crayones, témperas. Se trabajará bidimensionalmente y de forma individual.

Desarrollo: Cada participante dirá su nombre en ronda y luego trabajará sobre la imagen de sí mismo.

\section{Sexto Encuentro}

\section{Consigna: Había una vez... Primera parte}

Objetivo: Ver como cada sujeto recibe y procesa el cuento que escucha, qué elementos toma para ilustrarlo. El cuento elegido se llama "¡Atrápalo Cisne!”

Materiales: Hojas canson grandes, fibras, crayones y témperas. Se trabajará bidimensionalmente e individualmente.

Desarrollo: Cada sujeto deberá plasmar en imagen aquellos elementos del cuento que más le hayan impactado. 


\section{Séptimo Encuentro}

\section{Consigna: Había una vez... Segunda parte}

Objetivo: Explorar la construcción grupal de una historia/cuento

Materiales: Papel de escenografía, lápices, crayones, témperas, cola de pegar, elementos de desecho. Se trabajará bidimensionalmente y de forma grupal.

Desarrollo: Los participantes deberán, por turnos, contar cada uno una parte de una historia que se irá hilando hasta formar una única historia que luego todos dibujarán/pintarán sobre una amplia hoja de papel de escenografía, acordando donde figurará cada elemento de la misma.

\section{Octavo Encuentro}

\section{Consigna: Nuestro Jardín}

Objetivo: Explorar diferentes modalidades de enfrentar la vida en ese nuevo mundo exterior al que se reintegrarán, a través de la creación de una flor individual colocada en una maceta y que formará parte del lienzo colectivo.

Materiales: Se utilizará como fondo de jardín una hoja extensa de papel de escenografía donde se pegará cada flor individual. Hojas canson grandes, fibras, lápices, crayones, témperas, papel crepe, tijera y goma de pegar. Primera parte individual y luego grupal.

Desarrollo: Los participantes trabajarán de forma individual, creando una flor en una maceta. Luego, dicha maceta será recortada y pegada en el lienzo grande, junto con las otras. Dos o tres participantes se ocuparán de pintar el fondo sobre el que se pondrán las macetas. Se les sugiere: un jardín, una terraza, un patio, una pared, un balcón.

Esta última consigna, de cierre, permite ver dónde se ubica cada uno, de acuerdo al tamaño de su maceta y de su flor, además de cómo elige representarse. También se toma en cuenta entre quiénes se ubica o si trata de encajar en un lugar en el que ya no hay espacio. Se observa qué espacio le da a los otros y cuánto respeta ese espacio. Finalmente, la riqueza o la pobreza de la representación dirán algo de su ejecutor. Lo elegí como trabajo de cierre porque permea un espíritu integrador y de convivencia.

Presenté un anexo con algunas consignas complementarias en caso de que la institución deseara extender la actividad. Como esto no sucedió, estas consignas no se realizaron:

\section{Consigna: Mi día}

Objetivo: Permite ver como cada participante se organiza y distribuye su tiempo, además de explorar cómo percibe las actividades que se realizan en el Hogar.

Materiales: Hojas canson blancas grandes, fibras, crayones.

Desarrollo: Cada participante trabajará sobre una hoja cuadriculada formando una grilla y en cada casillero dibujará una actividad o situación de su día, luego elegirá el momento que más le haya gustado y el que menos le haya gustado.

\section{Consigna: Un lugar para vivir}

Objetivo: Construir con un compañero un lugar para vivir. 
Materiales: Bloques de poliestireno expandido, sobrantes o recortes de cartón, madera, o cualquier material de desecho, cajas pequeñas vacías, alambres, cartulina, fibras, crayones, cinta de enmascarar y cola de pegar.

Desarrollo: Entre dos niños deberán acordar las características del lugar más adecuado para vivir, abocándose a su construcción con los materiales provistos.

\section{Consigna: Un lugar para convivir}

$\underline{\text { Objetivo: }}$ Abocarse a la construcción grupal de un barrio donde convivir con los otros niños.

Materiales: Se utilizarán las casas construidas en la sesión anterior que se interconectarán con cola de pegar. Luego habrá una cantidad de material disponible para recrear el barrio.

Desarrollo: El grupo trabajará sobre una gran plancha de cartón que servirá de base para ensamblar las casas armadas en el encuentro anterior, además de crear los elementos que permitan identificar un barrio (aceras, árboles, semáforos, negocios, plazas, etc.)

La única consigna que no fue tomada en cuenta por el grupo fue la séptima, la de la construcción grupal de un cuento. Antes bien, todos acordaron ilustrar escenas de una película que les habían llevado a ver al cine, la de un auto mágico llamado Herbie. Y cada uno tomó una escena en particular, siempre representando al auto mágico.

En el desarrollo de este proyecto he tratado de comenzar desde lo individual, con las percepciones internas y externas, la presentación del sujeto y la visión de sí mismo y de lo que lo rodea, pasando luego a la actividad grupal de carácter integrador, fundamentalmente propiciado por las consignas "Las manos que hablan", "Había una vez Segunda parte" y "Nuestro Jardín"

Consideré que la presentación de cada uno de manera visual, debía estar ubicada hacia la mitad del proyecto, ya que era necesario que se estableciese un vínculo de confianza. Por lo que las primeras consignas exploran temas relativamente generales antes de abordar la representación - en muchos casos problemática - de sí mismos.

En cuanto al cuento elegido para el sexto encuentro, "Atrápalo Cisne", la elección se debió a que el protagonista poseía cualidades como: alegre, simpático, bueno y generoso. Además de dos cualidades que resaltaban sobremanera: altruismo y solidaridad. La figura de los abuelos aparece antes de que la de los padres (algo importante en niños con padres que pueden estar presos o internados o con quienes el vínculo haya sido de violencia).

El cuento narra la historia de un muchacho muy pobre que, al asistir a una anciana que encuentra en un bosque y con la que comparte su comida, en agradecimiento recibe un cisne y una varita mágica. Todo el que toque al cisne y ante las palabras mágicas "Atrápalo Cisne", quedará pegado a él. Fue tal la cantidad de gente que terminó pegada al cisne que, en la plaza del pueblo, logró atraer la atención de una princesa triste que rió a carcajadas ante tal imagen, logrando que su padre el Rey le otorgase su mano al muchacho por haberla curado de su depresión. El muchacho libera a todos los que estaban pegados a la cola del cisne con la varita mágica y se casa con la princesa. 
El cuento posee dos frases clave que generan resonancias con este tipo de población: "mi riqueza y mi poder residen en la alegría de mi corazón, es una riqueza que no disminuye cuando se reparte, al contrario, aumenta." $\mathrm{Y}$ la segunda: "Me gustaría ser príncipe por un solo motivo: ayudar al prójimo y sembrar alegría."

Citando nuevamente a Edith Kramer, en el trabajo arteterapéutico con niños institucionalizados es importante tener en cuenta que:

En muchos casos, la personalidad de los chicos está tan poco estructurada que carece de los sentimientos de auto identidad y de integración necesarios para asimilar las experiencias y volcarlas en una forma coherente. Esos niños están atormentados por sentimientos de vacío y de soledad. Detrás de los estereotipos de espadas y escudos, calaveras y tibias cruzadas, corazones, cruces, pulpos o jefes de indos, no sólo se esconde un pequeño niño asustado disfrazado de hombre grande y poderoso, sino más bien un ovillo de confusión y contradicción que todavía no se ha transformado en individuo.... La adhesión a simples formas simbólicas como una cruz, un escudo o un corazón es a menudo un primer intento del niño de crear algo propio que simbolice y pruebe su existencia. (Kramer, 1982: 96, 97).

\section{Desarrollo del taller}

En el primer encuentro hubo dos cuestiones que dieron cuenta de ciertas particularidades a considerar en el trabajo con esta población: varios niños llegaron a pedir entre cinco y siete hojas para trabajar, produciendo múltiples trabajos nacidos más de la ansiedad y la expectativa que de lo creativo. Y luego, en cuanto se colocaron los materiales sobre la mesa, hubo una guerra de lápices y fibras, en la que muchos materiales resultaron dañados.

Como no se encontró un lugar para guardar los materiales ni los trabajos en toda la institución, a cada encuentro llegaba y me iba cargado, situación que quienes hemos trabajado en instituciones psiquiátricas conocemos muy bien.

Pero me voy a centrar, en primer lugar, en los trabajos del grupo de tres hermanos, del que revisaré primero la obra de Julio, un niño de 8 años, luego, la de su hermana Laura, de 9 para terminar con la obra del más pequeño, Carlitos, de 5 años.

\section{Estudio de casos}

Julio (8 años)

En "Mis Cosas Favoritas", comenzó dibujando en el centro de la hoja un gran plato de patatas fritas y, antes de continuar con la línea de alimentos como el resto de sus compañeros, dibujó una gran casa de la que dijo "tiene un fuego para dormir al lado", el fuego es, junto con un jarrón con dos flores, lo único a lo que aplicó color, más abajo hizo una casa igual pero más pequeña donde aparece el mismo jarrón con dos flores, pero aquí no hay color. Luego continuó con el dibujo de los 
alimentos. Al finalizar, me dijo: "escríbeme la fecha detrás, pero dámelo después porque yo soy el que tiene que firmarlo."

Luego me pidió otra hoja, más pequeña, donde retomó el tema de la casa con el fuego y el jarrón con las dos flores, en una suerte de ampliación casi exacta de la gran casa del primer trabajo con la diferencia de que las ventanas ahora tienen una línea en el centro que las presume como cerradas. Este segundo trabajo me lo regaló. Al final del encuentro de ese día me entero por la secretaría que él y sus hermanos estaban algo expectantes porque su padre hacía ya tres fines de semana que prometía venir a buscarlos para un paseo y no venía, aduciendo que no tenía plata, ni tiempo.

Para el tercer encuentro, "Jugando con Máscaras," Julio hizo una máscara de Batman. De este superhéroe dijo que "lucha por el bien y salva las vidas". Ese trabajo también me lo obsequió.

El resto del grupo también trabajó superhéroes, ya por su aspecto salvador como por su aspecto redentor, como una niña de 11 años que hizo la máscara de Catwoman de la que dijo: "de día es una chica común y corriente y de noche se transforma en Catwoman, roba y no se da cuenta de que roba... aunque después lo devuelve."

En la consigna del cuarto encuentro, "Las manos que hablan," Julio puso gran empeño en sus manos, pero una de ellas la dibujó con los dedos pegados, mientras en la otra están separados. Ambas manos son coloridas pero, al momento de pegarlas en el lienzo colectivo en forma de mandala, insistió en ponerlas fuera del círculo. Hablé un rato con él, tratando de negociar la importancia de la inclusión de sus manos en el trabajo, como una forma de dejar una huella, de integrarse al grupo. Finalmente aceptó incluirlas con el resto pero no les puso su nombre.

Al comenzar el quinto encuentro, se me informó que Julio estaba recluido en el dormitorio. Luego de ser autorizado para subir a buscarlo, lo encontré sentado en el piso, reticente a hablar y sin ganas de trabajar. Le ofrecí llevarle materiales allí para que al menos pudiese aprovechar el encuentro. Finalmente accedió a bajar, pero trabajó separado del grupo, en una mesita pequeña que había en una esquina de la sala.

En "Hola yo soy...," (FIG 1) Julio se presenta dibujándose a sí mismo pero también me hace a mí en reflejo con él y en la parte superior de la hoja escribe: "Julio y Luis fueron el domingo a ver la pelea". Ambos aparecemos sacando la lengua y vistiendo dos prendas iguales, de color azul, negro y verde. A mí se me reconoce por los lentes. En la parte inferior puede verse el ring donde acontece la pelea que fantasea fuimos a ver. Al terminar este trabajo, hizo otro, que me regaló nuevamente, y en el que aparece la casa de una de las sesiones anteriores, pero dentro ahora coloca su nombre y el mío. El trabajo me lo entregó doblado, como si fuese un sobre. 


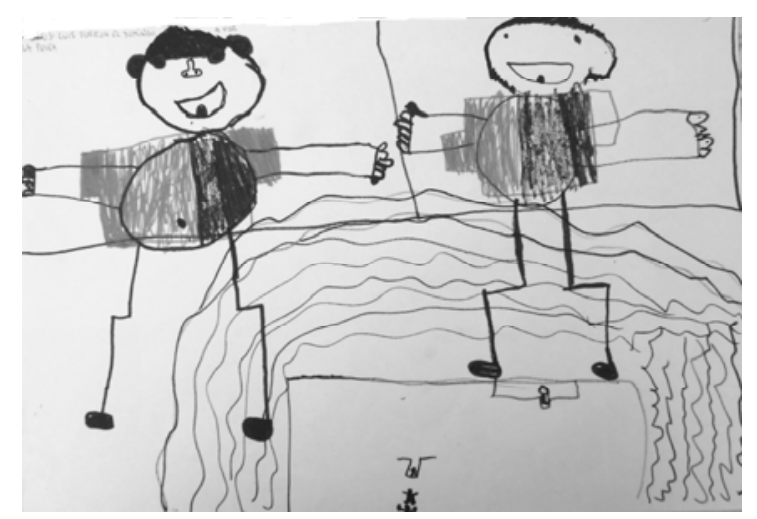

Figuea 1 "Hola yo soy..."

Este trabajo me alertó sobre la transferencia masiva que se estaba dando en Julio y me obligó a examinar mi contra transferencia, ya que me sentía movilizado y apabullado por semejante demostración. ¿Cuál es el límite óptimo para no quedar atrapado en ese enjambre de proyecciones y deseos?

En la representación del cuento Atrápalo Cisne, cuya consigna era "Había una vez," Julio tomó la imagen del héroe y lo hizo al cobijo de un árbol. El tronco del árbol ocupaba casi toda la hoja y estaba como encapsulado, asemejando una gigantesca puerta o espacio protector a cuyo pie estaba el héroe del cuento en un tamaño diminuto. Este es el único trabajo que Julio coloreó.

El último encuentro fue altamente movilizador para Julio, quien no quiso trabajar en la consigna y se encerró en el servicio golpeándose la cabeza contra la puerta desde dentro. Ninguna de las asistentes supo cómo manejar la situación. Desde fuera yo le hablé con calma hasta que accedió a abrir la puerta, solo para salir corriendo hacia los dormitorios.

Si bien no le di un trato diferente al de los demás niños y mantuve una distancia óptima, no pude evitar ser puesto en el lugar de ese padre ausente y, con el cierre de la actividad, yo también lo abandonaba.

Desde el comienzo Julio se colgaba de mí al rato de haber llegado a la institución. Y muchas veces, mientras trabajaba, buscaba mi mirada como esperando cierta aprobación.

Caroline Case se refiere a dos niveles transferenciales, y del segundo dice:

El segundo nivel de interacción se refiere a la transferencia entre el arteterapeuta y los miembros del grupo y entre los miembros entre sí. Las relaciones transferenciales pueden ser entendidas como sentimientos y deseos experimentados alguna vez en relación a figuras significativas del pasado... La transferencia también estará implícita o explícita en las imágenes. (Case, 1992: 228, 229) 
Ese dibujo que hace Julio en el que ambos vestimos igual da cuenta de una transferencia explícita.

Laura (9 años)

Hermana de Julio y un año mayor que él. Aunque de carácter retraído, sus producciones dan cuenta de las características de la "etapa realista", si se las mira desde las etapas de evolución del grafismo, de V. Lowenfeld. Con pleno uso del color y un correcto manejo de diversos materiales, sus trabajos permiten anticipar un potencial creativo. Además, era quien, al finalizar cada encuentro, ordenaba la mesa y colaboraba en el guardado de los materiales. A diferencia de su hermano, en "Mis cosas favoritas," se centró en la comida, ordenadamente representada, además de circundar la hoja con una guarda de círculos y líneas que coloreó con delicadeza.

Su máscara es la de Violeta, personaje de Los Increíbles, de la que dijo "ella forma una burbuja para proteger a su familia y se hace transparente, o sea, está, pero desaparece, y así, salva al mundo." No es casual la elección de esta heroína, ya que como hermana mayor, protegía a Julio y al menor de la familia, Carlitos, de cinco años. Los tres siempre a la espera de un padre que no cumplía su promesa de visitarlos.

En "Las manos que hablan", éstas presentan atributos extras como una pulsera y un reloj, y en cada uña, escribió las letras que forman su nombre - a diferencia de su hermano, que no quiso poner su nombre. Así de detallado fue el dibujo de sí misma en "Hola yo soy...", (FIG 2) su imagen, hermosamente dibujada aparece sobre un aguado fondo verde, y es de interés notar que en la pupila de cada ojo se puede ver una estrella.

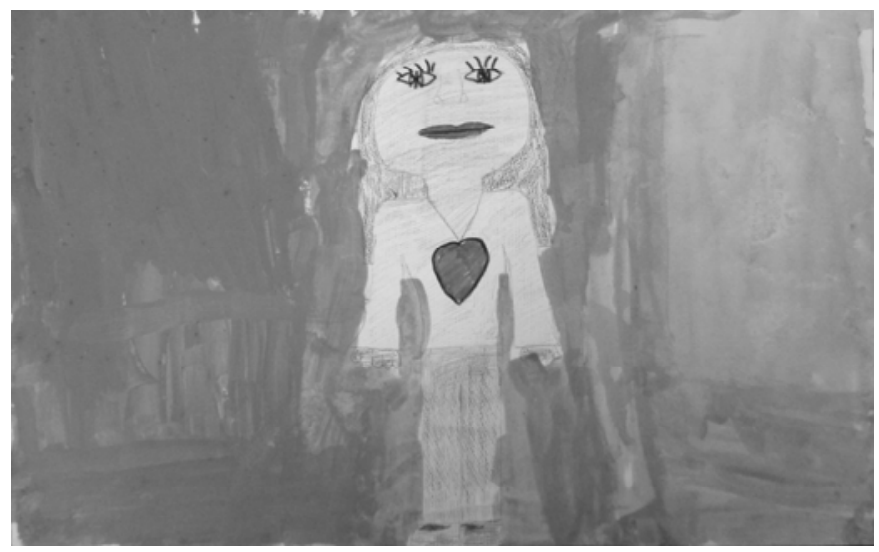

Figura 2 "Hola yo soy..."

Su representación del cuento Atrápalo Cisne, colocó a este último en el centro de una escena simétrica, con dos árboles, uno a cada lado de la hoja, una nube azul sobre cada árbol y un radiante sol en el centro. Su nombre y la fecha figuran en el centro de la hoja, entre el sol y el cisne, otorgándose un protagonismo central en la imagen final. Da cuenta de un mundo ordenado y simétrico. 
Su creatividad me llevó a preguntarme cuál sería el destino de estos niños y si pudiesen seguir desarrollando esa creatividad. Qué oportunidad preciosa se malgasta cuando las intervenciones en arte son desestimadas o no se las estimula, qué manera tan desafortunada de obturar la posibilidad de encontrarse consigo mismos a través de la imagen, para así comprender, aceptar e integrar el mundo, aun siendo doloroso como el de estos niños.

\section{Carlitos (5 años)}

En cuanto al más pequeño, fue el único de todo el grupo quien en "Mis cosas favoritas" no dibujó alimentos sino que hizo una gran casa a la que a último momento y luego de haber entregado el trabajo, le hizo una chimenea con humo saliendo de ella en dos direcciones. No solamente coloreó la casa, y en especial sus ventanas, sino también el fondo de la hoja, de gran tamaño y sin utilizar el crayón de punta.

En "Jugando con máscaras", utilizó recursos tal vez impensables para un niño de tan corta edad. Habiendo hecho los ojos en la máscara, decidió taparlos, primero con abundante cinta de papel del lado de atrás y luego agregando más cinta en la parte de adelante para que no se vieran en absoluto. Cuando pidió asistencia con la tijera para hacer un nuevo par de ojos debajo de los primeros, quedó en claro que se dio cuenta que los había hecho demasiado altos. La figura tiene un prominente bigote hecho con lana de vidrio en rollo y logró hacerle los pelos de punta cortando la parte superior del cartón corrugado en tiritas.

"Las manos que hablan" muestran sus dos pequeñas manos con el detalle curioso de que la mano izquierda tiene enrojecido el dedo pulgar y la derecha, el dedo índice.

La representación de sí mismo fue simpática y graciosa, se hizo sonriendo, con una mata de cabello azul que pendía sobre su cabeza como una nube. Lo curioso es que produjo un segundo trabajo en el que hizo al padre, ese padre que nunca viene a verlos ni a buscarlos para pasear.

Del segundo grupo de hermanos tomaré en primer lugar a Raquel, de 7 años (hermana de Esteban, de 9 años) y del bebé de un año.

\section{Raquel (7 años)}

Se presentó como la más tímida y retraída del grupo. Al comienzo, al terminar los trabajos, los entregaba cara abajo y pedía que el grupo no los viera. No hablaba sobre su producción, escondiéndose detrás de cada obra. Para "Un día de salida" hizo cinco trabajos, en los que fue desde la desorganización hacia la integración. En el primero hay elementos en lápiz desperdigados por el espacio central de la hoja, en la que solo colorea los bordes de cuatro colores diferentes y lo que parecería ser un escudo de un equipo de fútbol en consonancia con lo que circulaba entre los varones. El segundo muestra un gran plano rojo superior y debajo, cuatro figuras humanas, alejadas entre sí, con una más prominente en tamaño que las otras - ¿los tres hermanos y uno de los padres?. En el tercer trabajo aparece una casita con una chimenea humeante - y un sol en lápiz y colorea con lápiz verde parte de la casa y el centro del sol. El cuarto muestra cinco flores, agrupadas de a dos, con una flor central más grande en amarillo, la casita ahora aparece diminuta en el extremo inferior izquierdo de la hoja, pintada de color marrón, todo sobre una superficie 
verde y una línea azul por cielo. Finalmente, el quinto muestra la casita, ahora sin chimenea, de la que sale una línea que parece tener ropa tendida (pero que si se la mira con detenimiento muestra tres hamacas con tres personitas hamacándose, pero desconcierta que no tenga parantes laterales, está literalmente en el aire) y del otro lado, solo tres flores. De la línea azul del cielo penden formas en lápiz, similares a las que aparecían desperdigadas en el primer trabajo.

De este trabajo se puede conjeturar que el último mostraría su estado actual: los tres hermanos jugando, del otro lado, los tres hermanos como flores y en el centro, la casa de acogida.

Para la segunda consigna, "Mis cosas favoritas", luego de dibujar la infaltable comida - en la que, por la diferencia en las representaciones se nota que fue asistida - hizo dos trabajos suplementarios sin conexión entre sí, en el primero se ven tres figuras hamacándose, ahora pueden verse los parantes que sostienen las hamacas, pero aun así, está en el aire, y el siguiente, solo realizado con fibras, muestra un sol, un corazón en el centro de la hoja que parece partido al medio y nuevamente una casa, sobre la cual dibujó líneas en azul que dan la sensación de tachadura.

Para "Jugando con máscaras", trabajó con suma rapidez, utilizando témperas y lana para el cabello. Cuando la terminó, corrió escaleras arriba a esconderla en el dormitorio. Luego de pedirle que la bajase para que al menos yo pudiese verla, lo hizo y lo significativo es que si bien siempre se escondía detrás de la hoja a la hora de presentar los trabajos, en esta oportunidad, aun rehusando hablar de la máscara, no se escondió detrás de ella. Luego hizo un segundo trabajo en una hoja pequeña en la que el esquema del rostro, representado por dos ojos, una nariz y una boca, aplicados en gruesos trazos de témpera verde, parecen flotar sin contorno en el blanco del papel. Este segundo trabajo tiene toda la apariencia de una mueca, de algo distorsionado. Al colorido de la máscara, le contrapone una imagen distorsionada.

Para el primer trabajo de puesta en común, "Las manos que hablan", hizo tres pares de manos, que recortó con una tijera que obtuvo de la Secretaría y que se negó a compartir con sus compañeros, aduciendo que era para ella, que la había tomado ella y que le pertenecía a ella. No fue fácil convencerla de que era imposible incluir tres pares de manos en un trabajo en el que cada compañero había puesto un solo par, las propias. Negociamos que podría incluir dos de los tres pares. Nuevamente, parecería que había tratado de hacer las manos de sus otros dos hermanos.

Para la consigna "Hola yo soy..." sucedió algo notable. Raquel le pidió a una compañera, Adriana, de 12 años, que la dibujara. La versión que Adriana hizo de Raquel, tiene algo de sí misma, pero será el modelo que Raquel va a utilizar para hacerse. Además, en esta versión, Raquel le pidió que incluyera el nombre de todas sus compañeras. Finalmente Raquel coloreó el dibujo que Adriana hizo de ella con pasteles al óleo.

En la representación de sí misma, sin embargo, rehusó usar color y solo garabateó con azul el vestido que lleva la figura. (FIG 3) 


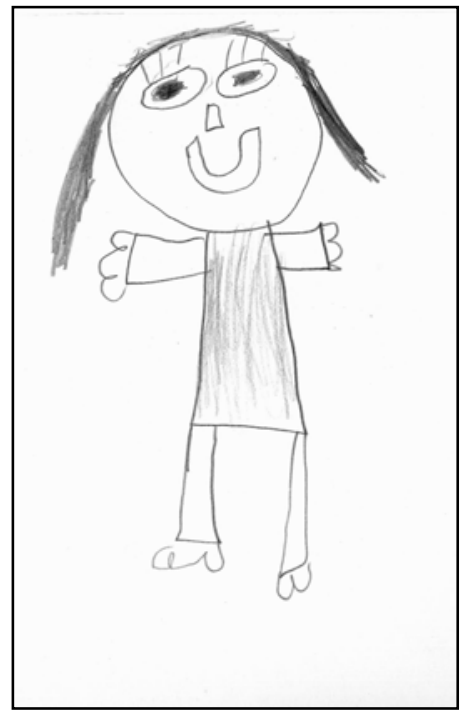

Figura 3 "Hola yo soy...."

Para el trabajo final "Nuestro jardín", Raquel hizo una hermosa flor que le obsequió a una de las mujeres que allí trabajaban, grande fue mi sorpresa cuando le dijo "La hice para vos mamá". Luego, hizo otra versión de la misma flor para colocar en el lienzo colectivo, trabajando, por primera vez, con total soltura y tranquilidad, como si haber identificado a su madre en ese entorno donde supuestamente no debía estar, le hubiese quitado presión de encima.

De acuerdo a las etapas de evolución del grafismo, Raquel debía estar ya ubicada en la etapa esquemática, sin embargo, sus trabajos carecían de línea de base $\mathrm{y}$ en tanto ubicación, el espacio remitía a una representación de tipo egocéntrico, característico de la etapa pre-esquemática. Su representación de las figuras y los colores, cuando los aplicaba, era de corte netamente emocional.

\section{Esteban (9 años)}

Para el primer encuentro sobre un día de salida realizó dos trabajos, trabajando a ambos lados del papel. Rescató una visita al circo - donde se ve una personita diminuta a la entrada de la inmensa carpa y del otro lado de la hoja, los colores de su club de fútbol favorito, algo que hablaban los varones en la mesa. Fue otro de los que dobló el trabajo en cuatro y se negó a entregarlo, hasta que finalmente cedió. Para "Mis cosas favoritas", no representó comida sino un paisaje urbano en el que se ven dos casas, un cielo plagado de nubes permite ver un gigantesco sol amarillo en la parte superior derecha, con lentes ahumados. Es lo único con color.

Su máscara, sin embargo, fue uno de los trabajos más fuertes y perturbadores que me haya tocado ver en mis años de trabajo con niños. El impacto estuvo dado por el hecho de que después de haberla terminado, y se trataba de un trabajo minucioso de corte de tiritas rojas que pegó en forma horizontal y vertical, hizo un bollo, se acercó a mí y me dijo: "acá tenés mi trabajo." (FIG 4) Y corrió a 
esconderse en el dormitorio. Recordé las implicancias de la destrucción de la propia obra, según Edith Kramer:

El sentimiento de los niños con respecto al hecho de pintar es ambivalente. El orgullo natural por el trabajo de sus manos se desmorona ante la subestimación general. El odio y el desprecio que guardan hacía sí mismos se expresa en la disposición para destruir su propio trabajo y el trabajo de los demás. Su baja autoestima les hace descalificar ideas y formas expresivas originales, tienen gran necesidad de conformidad y perfección convencional. (Kramer, 1982, 46, 47)

Cuando desplegué el trabajo puede ver una imagen desfigurada, que suscitó diversas emociones en mí. Este niño tiene VIH - algo que no me fue informado pero cuyo esquema de toma de medicación pude observar en una pizarra en la oficina donde tuve la entrevista inicial.

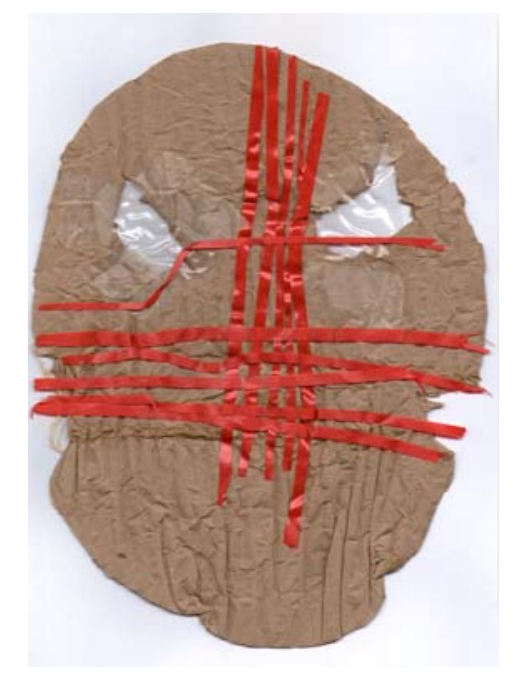

Figura 4 "Jugando con máscaras"

Por supuesto que pedí autorización para subir al dormitorio y allí lo encontré, acurrucado en un rincón. Me acerqué y sin mediar palabra, lo abracé. Le dije que aunque a veces creamos que un trabajo no nos sale bien, su trabajo era muy bueno y que lo tenía conmigo para que juntos pudiéramos repararlo. Lo abrí nuevamente, sobre el piso, y entre los dos alisamos la bola de cartón corrugado. Esto lo tranquilizó y accedió entonces a bajar a la zona de trabajo que ya estaba preparándose para la merienda de la tarde.

Esta reparación fue muy importante, le adjudicó a la obra un valor que había sido desestimado y se adjudicó, consecuentemente, ese valor a sí mismo.

A la semana siguiente, con "Las manos que hablan", Esteban se mostró muy comunicativo y trabajó concentradamente en sus dos manos, de las que me llamaron la atención que aplicó témpera roja en la punta de los dedos (a la manera 
de las líneas rojas en el rostro del trabajo anterior). El resto de las manos lo dejó en blanco.

En "Hola yo soy...." fue el único que no acató la consigna e hizo una secuencia como de historieta en cuatro escenas que numeró, en ellas pueden verse: casas - o más bien edificios - en el desierto, dos pequeñas y una más grande, luego aparece el sol, sonriendo y nuevamente con lentes ahumados, en la tercer secuencia, más casas, tres, pero ahora con el agregado de serpientes y cactus y finalmente solo serpientes - una enroscándose - y más cactus, por fuera de los cuadros se ve como una suerte de ruta por la que circulan autos. Toda la escena fue definida por Esteban como "un lugar para jugar".

Muy interesante es su representación del cuento "Atrápalo Cisne", tomó la figura del árbol "que tiene cortadas las ramas," aclaró y le pidió ayuda a una de las niñas para dibujar la carroza donde iba la princesa triste. Esta vez, el sol no tiene lentes ahumados (había hecho un sol anterior que borró), y parece más una gigantesca cara sonriente que pende sobre el árbol. El árbol, en una copa con forma romboidal, tiene pequeñas manchas rojas. También aparecen el héroe con la varita mágica, la comida, la abuela y el cisne, todos hechos diminutos en comparación con el árbol, que tiene como círculos en su tronco y unas raíces rígidas que dibujó por debajo de la línea de base. El marrón de las raíces y el rojo de las manchas en la copa del árbol son los únicos elementos que coloreó en el trabajo.

Del tercer grupo de hermanos, vamos a ver los trabajos de Diego.

\section{Diego ( 9 años)}

Fue uno de los que más ansiedad demostró el día que comenzó el taller, haciendo siete trabajos en poco tiempo, los tres primeros son los que respetaron la consigna de "Un día de salida", el cuarto fue el dibujo del Jedi de La Guerra de las Galaxias que me lo dedicó a mí. Como se aproximaba la hora de paseo por el parque, el grupo empezó a querer irse, pero Diego se levantó, se paró a mi lado y dijo que quería seguir dibujando. Finalmente logró que todos se quedaran. Hizo entonces su quinto trabajo, que me lo dedicó porque respondí la pregunta de mi club de fútbol favorito. El sexto trabajo ilustra un partido y el último, también dedicado a mí, porque me dibujó llegando a la actividad y en la parte inferior de la hoja, se hizo él sentado dibujando.

Para "Mis cosas favoritas," se apartó de la comida - que fue la imagen más popular - e hizo una escena de una película que él llamó "Llegó el recreo."

Sus manos, para el primer trabajo colectivo, parecían pezuñas, con uñas en punta, afiladas, luego, en una hoja aparte hizo lo que describió como "la mano cuchillo."

Para "Hola yo soy..." se presentó con una pomposa dentadura y una amplia sonrisa que según él se debía a que en ese momento le estaban cortando el pelo.

Es muy interesante su representación del cuento, en el que la figura prominente es el cisne, que ocupaba el centro de la hoja, por detrás, el árbol, del que vemos mayormente el tronco y muy arriba se atisba algo de la copa. También incluyó la varita mágica. Pero lo más notable es que estampó su mano, la que previamente embadurnó con témpera y dijo que era la mano del príncipe. 
Para el trabajo final, utilizó tres planchas de goma eva que le permitieron componer un cuerpo, al que le agregó brazos abiertos y piernas. Lo colocó en medio de las macetas con flores y logró así, humanizar y protagonizar ese jardín colectivo.

\section{Claudio (5 años)}

El único del grupo sin hermanos en el hogar, tuvo participaciones esporádicas. En el segundo encuentro "Mis cosas favoritas" hizo una representación de la comida, sin ver que el resto estaba haciendo lo mismo. Estaba sentado en una mesita aparte y cuando finalizó me describió "pan, hamburguesa, dos panes, una empanada, un pan grande". Situado aún en la etapa del garabato, probó ser muy rápido en sus movimientos e inquisitivo. Por ejemplo, abrió una caja donde había materiales guardados, tomó un sacapuntas y se dedicó a sacar punta a los lápices de colores sin parar.

Con la ayuda de una de las niñas de más edad, hizo una interesante máscara que pintó de verde, en su balbuceo de niño tan pequeño y con una nariz siempre llena de mucosidad dijo "el increíble Hulk, pega fuerte". Probó tener recursos al utilizar un lazo de cinta roja como bigote y lana de vidrio como barba. Demandaba continuamente que le llenara la paleta con suficiente color para pintar.

Sus diminutas manos contaron con la asistencia de otra de las niñas para "Las manos que hablan", una vez silueteadas y recortadas, las coloreó con cuanto color había. En un momento mencionó la palabra "caca". Pregunté a la asistente si necesitaba ser cambiado y me contó que lo habían tenido que llevar al hospital y que allí se había hecho caca encima, al no tener ropa extra para cambiarlo, el hospital proveyó un pantalón que había pertenecido a un chico más grande que él y por eso tenía dificultades para caminar, no se los habían doblado y se los pisaba a cada paso que daba.

En "Hola yo soy..." se representó mediante el típico renacuajo.

\section{Conclusiones}

El abordaje arteterapéutico con niños institucionalizados implica - por las características de estos niños - monitorear de continuo los aspectos transferenciales y contra transferenciales, más allá de lo que las producciones puedan significar, especialmente si se trata de un proyecto acotado en el tiempo y más aún si la institución no lo continúa.

Las consignas que se propongan han de ser lo suficientemente lúdicas como para permitir la libre expresión de ese caleidoscopio de emociones y sentimientos que, tal vez, no encuentran una forma adecuada a través del lenguaje.

Lamentablemente, en ningún momento durante el tiempo que duró la actividad se evidenció el menor interés en lo que los niños producían. Nadie pidió ver los trabajos ni hacerlos circular en el equipo multidisciplinario.

La institución tampoco quiso quedarse con los trabajos de los chicos. Los trabajos colectivos tuvieron alto impacto en el grupo, los niños solicitaron que quedasen colgados en la pared, algo que tenía un sentido mucho más profundo que el meramente decorativo. La respuesta fue negativa, se me pidió una fotografía 
pequeña de esos trabajos para ser enmarcada y colgada en la pared. Nuevamente citando a Edith Kramer:

La identificación de los chicos entre sí es facilitada por sus pinturas. La comunicación a través de ellas es una nueva situación que rompe el aislamiento de los niños y crea una nueva clase de comprensión entre ellos. Pero las sesiones de arteterapia no bastan para que se produzca la identificación de los niños entre sí. Se necesita una zona más amplia, más neutral, alejada de la irritación y la frustración del acto creativo mismo. Una exhibición de los trabajos es el medio más eficaz para despertar un espíritu de aceptación e identificación mutuas. (Kramer, 1982: 47)

Aun así, este breve atisbo en el mundo de esos niños, con sus temores y esperanzas, fue una gratificante experiencia que, espero, haya contribuido a sembrar la semilla de lo creativo y de la expresión artística como un medio para el fortalecimiento yoico.

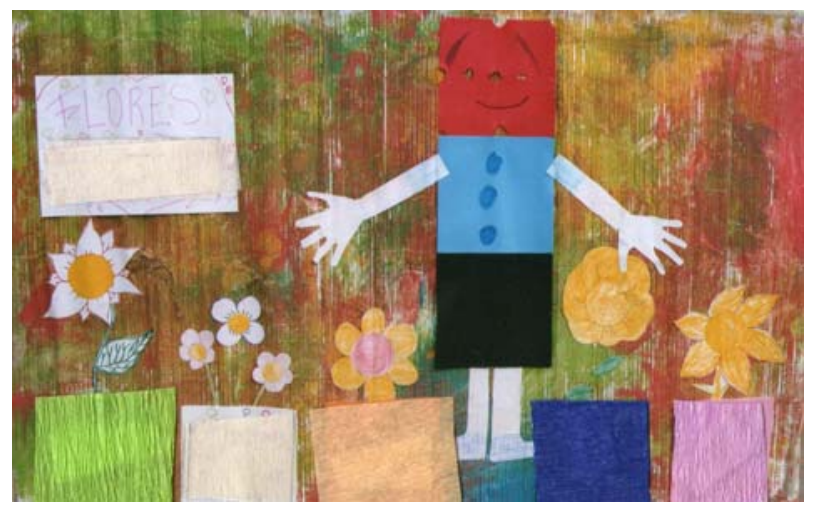

Figura. 5

\section{Referencias bibliográficas}

Anderson, F. (1992) Art for all the children. Illinois. Charles C. Thomas Publisher Case, C. \& Dalley, T. (1992) The handbook of Art Therapy, London, Brunner - Routledge Klein, J.P. et al (2012) Arteterapia, la creación como proceso de transformación, Barcelona, Octaedro

Kramer, E. (1982) Terapia a través del arte en una comunidad infantil. Buenos Aires. Ed. Kapelusz

Llompart, P. y Zelis O.P. (2008) El valor del arte para el desarrollo subjetivo. Buenos Aires. Letra Viva

López Fernandez CAO, M. y Martínez Diez, N. (2006) Arteterapia. Conocimiento interior a través de la expresión artística. Madrid. Ediciones Tutor

Marxen, E. (2011) Diálogos entre arte y terapia. Del "arte psicótico" al desarrollo de la arteterapia y sus aplicaciones. Barcelona. Gedisa Editorial

Pain, S. (2008) En sentido figurado. Fundamentos teóricos de la arterapia. Buenos Aires. Paidós 